\title{
Condensation phenomena and frost problems in the air heat recuperators
}

\author{
Mariusz Adamski ${ }^{\text {a }}$, Paula Kiszkiel \\ Faculty of Civil and Environmental Engineering, Bialystok University of Technology, \\ 15-351 Bialystok, ul. Wiejska 45E, Poland
}

\begin{abstract}
Investigation results of condensation phenomena and frost problems in the ventilation heat recuperators are presented. The experiments have been conducted for typical value of indoor temperature $20^{\circ} \mathrm{C}$ and a large range of humidity values from 20 to $75 \%$ and more of an exhausted air. The heat exchanger worked in the real conditions of the winter climate in Bialystok.
\end{abstract}

\section{Introduction}

Recuperators are widely used to heat recovery in ventilation systems of the buildings.

Regarding condensation phenomena, results of heat transfer and pressure drops investigation during heat recovery are presented. The experiments have been conducted for longitudinal flow spiral recuperators $[1,2]$ for different humidity values $\varphi$ of removed air in range 20 - 75\% and more. The stand and experimental procedure are described [2] and used to recuperators tests.

To explain the condensation process a $\mathrm{h}-\mathrm{x}$ diagram is used. The starting points are the conditions of air entering the recuperator.

Theoretically calculated temperature profiles in channels of the counter flow heat exchanger with phase change one or both fluids are presented in paper [3]. Four basic mechanisms of condensation are generally recognised [4]: dropwise, film-wise, direct contact and homogenous. A vapour or vapour/gas mixture will condense to a liquid on any surface that is even slightly below the dew point temperature of the vapour at the existing pressure [5]. This is true even if the vapour is highly superheated or multicomponent. In the latter case, the dew point decreases as condensation proceeds. In dropwise condensation, the vapour initially condenses as multitudes of tiny droplets on preferred sites on the surface. The droplets grow rapidly by conduction through the droplet until gravity or vapour shear overcomes surface tension and the droplets run off the surface. As long as the surface remains non wetting, the cycle is repeated. Dropwise condensation gives heat transfer coefficient as high as $60000 \mathrm{~W} / \mathrm{K} \mathrm{m} 2$ for steam.

Most surfaces are initially non wetting because of residual shop oil or other surface contamination, but become wetting after short time, typically a few hours. Once the surface is rendered wetting, film-wise condensation dominates with substantially reduced

\footnotetext{
${ }^{\mathrm{a}}$ Corresponding author: mariusz.adamski@pb.edu.pl
}

coefficients. Attempts to maintain a non wetting surface by introducing promoters such as metallic stearates or by coating the surface with a thin film of Teflon have proven operationally impractical. When the condensing surface is completely wetted, the condensate film flows under the influence of gravity and vapour shear and its heat-transfer characteristics can be reasonably predicted from hydrodynamic principles. This is the usual mode for condensation.

Direct-contact condensation occurs when a subcooled liquid is sprayed into the vapour or allowed to flow down a structural surface in a vapour space. Condensation occurs directly on the surface of the coolant. Heattransfer rates are strongly dependent upon the sprayer characteristics and particular structured surface.

Homogenous condensation (fog formation) - if vapour can be sufficiently subcooled without contact with a surface, a liquid phase can form spontaneously.

Based on summation of the dissipation energy coming from the flow in absence of bubbles and the dissipation contribution from the bubble motion shearing are obtained [6] the shear stress of equivalent single phase flow. An approximate solution to the model is given in a form of an explicit differential equation, which can be solved with an assumption of constant or variable void fraction distribution. Also a model of void migration is proposed. The model consists of five differential equations describing the velocity profile, shear stresses, lateral velocity, void fraction and temperature profile.

\section{Experiment}

In the tested recuperators may occur dropwise, film-wise and homogeneous mechanisms of condensation.

Recuperators' test stand has been shown and described in the paper [2]. Measurement results in cases where the condensation was negligible are given in $[1,2$, 
7]. The measurements were performed under conditions that respond to real working conditions of the recuperators.

Measurement results of the tested recuperators give combined effect of particular types of condensation and hoarfrost layer creation in recuperator channels. In paper [1] are presented pressure drops versus volumetric flow rate also in case of icing. Figure 1 shows frosted outlets of the channels.

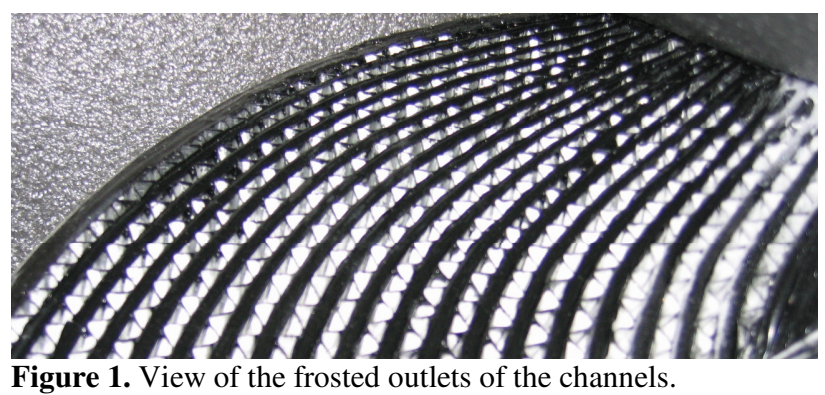

\section{Results and discussion}

Measurement results of the pressure drops of the exhausted air are presented in Figure 2. Air flow is laminar in the tested range of flow velocities in the channels of recuperators and pressure drops $\Delta p$ can be approximated versus the volumetric flow rate $V$ by the following equations:

For one phase flow

$$
\Delta p=1,1033 \mathrm{~V}-20,721, R^{2}=0,8817
$$

Constant value in the above equation results from a chimney draft in the room, an average value of about $21 \mathrm{~Pa}$.

For flow with frost creation

$$
\Delta p=-0,804 \mathrm{~V}+406,4, R^{2}=0,9492
$$

Constant value in the above equation results from a flow characteristics of the fan. Flow with condensation (Figure 2) is an intermediate zone between the above two flows. Registered pressure drops values are in range to $250 \mathrm{~Pa}$ for flow even $300 \mathrm{~m} 3 / \mathrm{h}$.

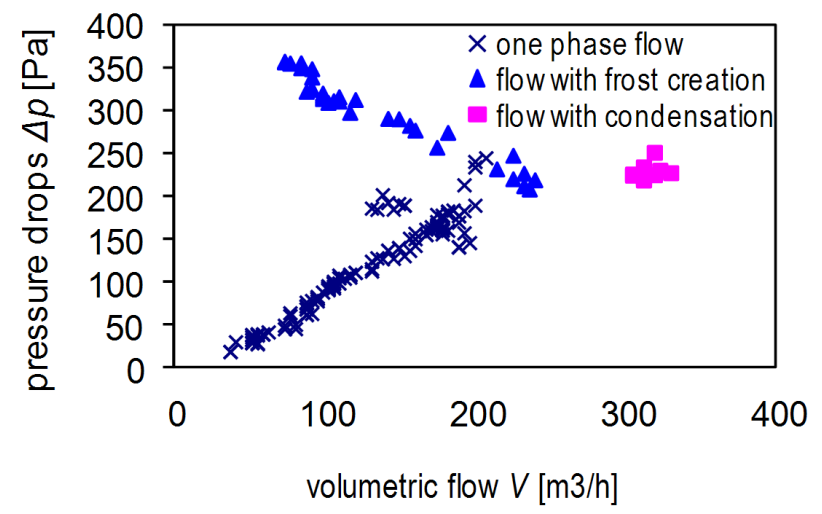

Figure 2. Pressure drops $\Delta p$ versus the volumetric flow rate $V$ of the cooled air $V$.

\subsection{Wall temperature profile}

Knowledge of the wall temperatures enables to separate particular zones (Fig. 3). Temperature and velocity profiles at particular cross sections of the cooled air channel are marked. Areas of the dropwise, film-wise, homogenous condensation and area of the frost creation are marked too. Longitudinal wall temperature has been designated for 1D flow of theoretical equations profile [3] with enough good accuracy. The results were compared with measurements performed thermocouple thermometer with an accuracy of $0.1 \mathrm{~K}$.

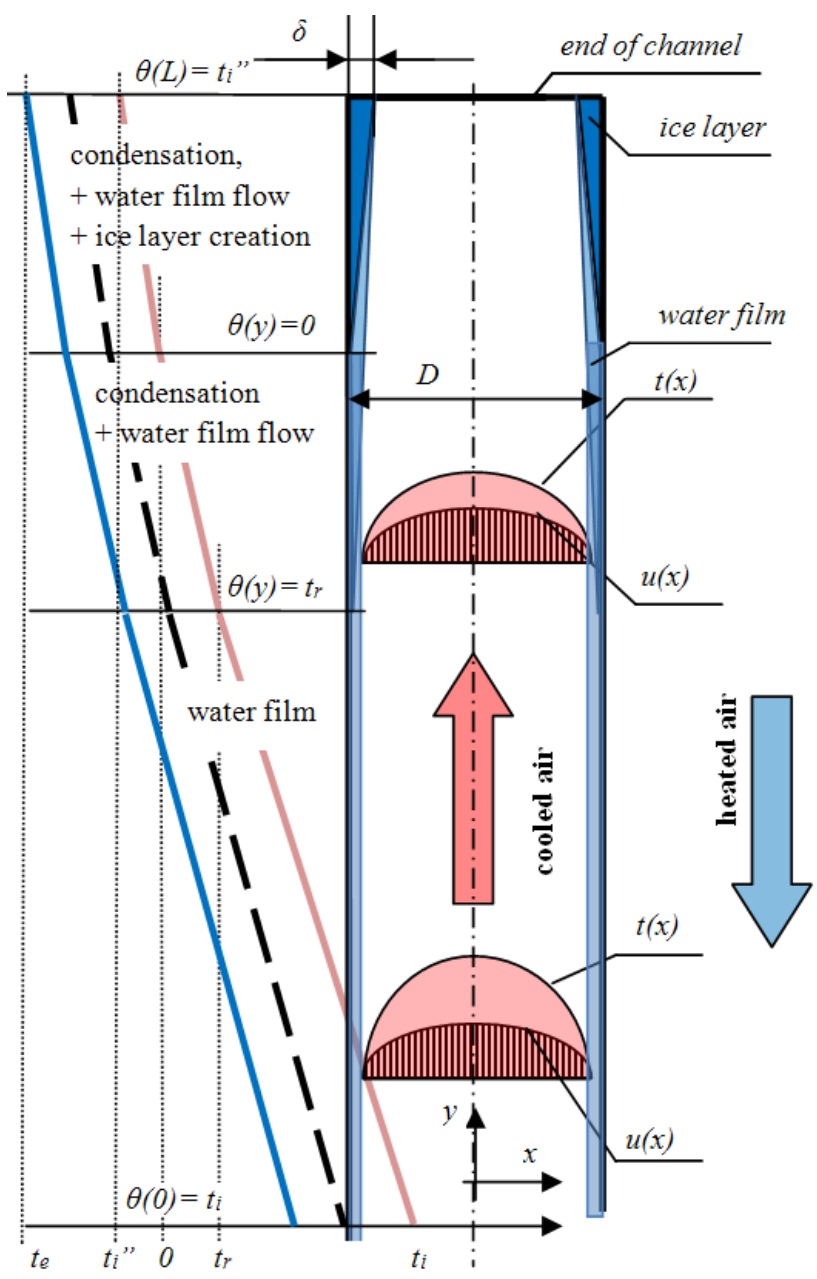

Figure 3. Particular wall temperature zones in vertical ducts of the recuperator.

\subsection{Increase in wall thermal resistance}

The water film has no significant impact an increase in wall thermal resistance because of the small thickness. Increase the thermal resistance of the wall is mainly due to increase in frost layer thickness. 


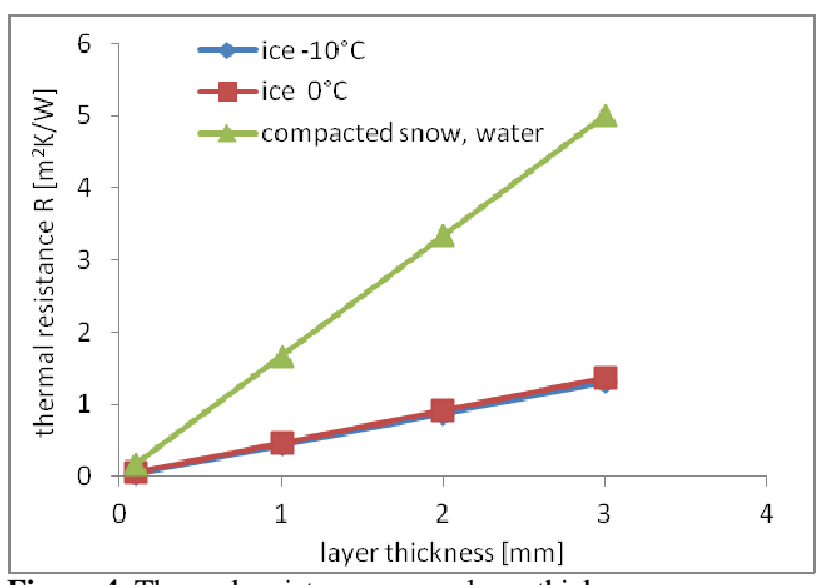

Figure 4. Thermal resistance versus layer thickness.

\subsection{Assessment of the efficiency of heat recovery}

The condensation phenomenon increases the temperature efficiency $\varepsilon$ of the recuperator and this is beneficial. This requires continuous removal the condensate from recuperator channels. The icing phenomenon through the creation of more and thicker frost layer increases pressure drop $\Delta p_{C F}$, reduces volumetric flow rate $V$ and leads to a decrease in the efficiency of the recuperator. Thermal efficiency of the recuperator with the thickness frost layer $\delta$ in the final part of the channel can be determined by the following equation

$$
\varepsilon_{C F}=n(\delta) \varepsilon
$$

The efficiency $\varepsilon$ is known and can be estimated [1, 2], similar $\varepsilon_{C F}$ is known from the measurements; hence the function $n(\delta)$ can be determined.

The function values $n(\delta)$ are in range of 0.9 to 1.1 .

\subsection{Pressure drops}

The water film has no significant impact an increase in pressure drops because of the small thickness. Pressure drops formula $\Delta p_{C F}$ in case of frost formation could be given in form

$$
\Delta p_{C F}=m(\delta) \Delta p
$$

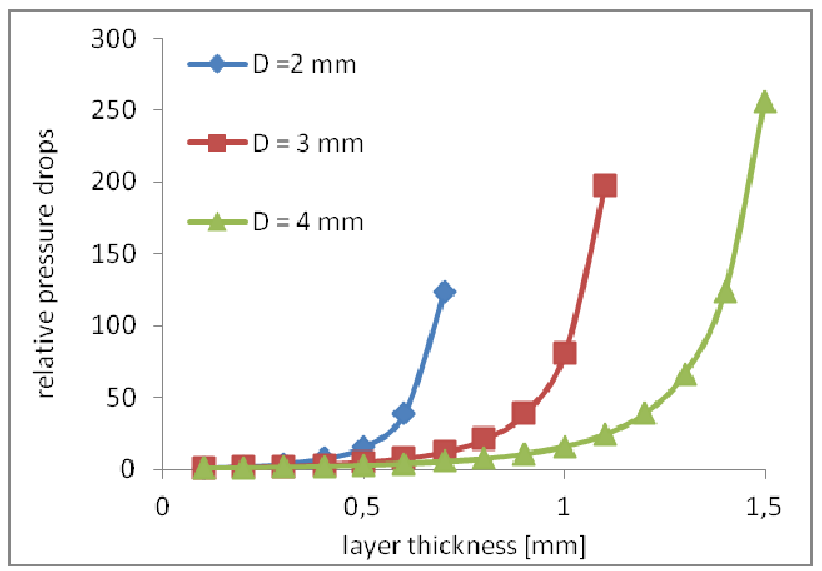

Figure 5. Relative local pressure drops versus local layer thickness.
If the ice layer is thin and regarding small part condensate volume could be assumed that velocity profiles are the same in particular cross sections.

From Hagen - Poiseuille law for incompressible fluids relative pressure drops $m(\delta(y))$ is given by formula:

$$
m(\delta(y))=[D /(D-2 \delta(y))]^{4},
$$

where $D$ - channel gap width, $\delta(y)$ - local thickness of the layer of frost, $y$ - coordinate along the channel axis (Fig. $3)$. Calculated values are illustrated in Figure 5.

If available is function $\delta(y)$ relative general pressure drops $m(\delta)$ for the whole exchanger could be calculated from formula:

$$
m(\delta)=\sum m(\delta(y)) \Delta y / L,
$$

where $L-$ channel length.

Relative general pressure drops versus volumetric flow rate are calculated (Figure 6) regarding obtained from measurements equations $(1,2)$.

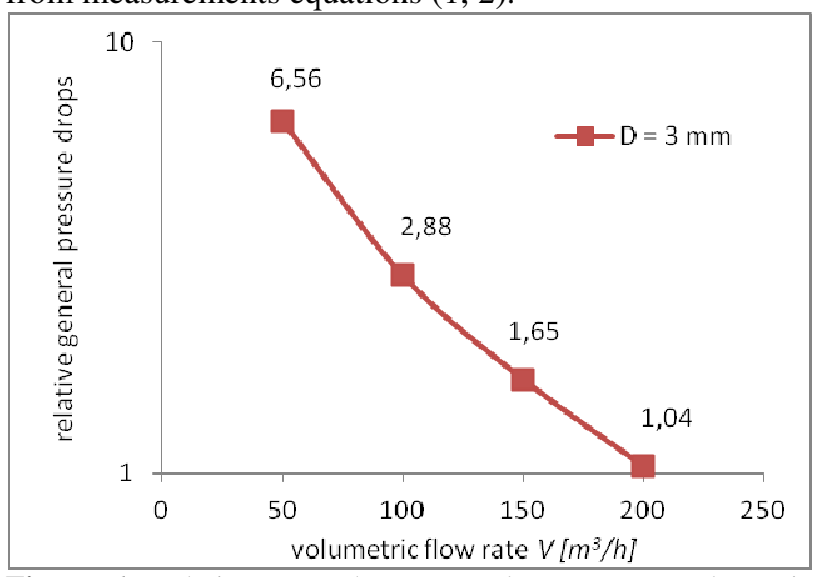

Figure 6. Relative general pressure drops versus volumetric flow rate.

\section{Conclusions}

In the high efficiency recuperators may occur dropwise, film-wise and homogeneous condensation.

Disadvantageous icing phenomenon occurs under specific conditions temperature - humidity removed air.

The detailed analysis of the functions $\mathrm{n}$ and $\mathrm{m}$ in quasi steady state conditions provides a quantitative assessment of the process of icing in the recuperator channels.

\section{Acknowledgements}

This study has been made within the frame of the Project No. S/WBiIS/4/2014.

\section{References}

1. M. Adamski, Ventilation system with spiral recuperator, Energy and Build., 42(2010), pp. 674677 
2. M. Adamski, Heat transfer correlations and NTU number for the longitudinal flow spiral recuperators, App. Therm. Engin., 29(2009), pp. 591-596,

3. M. Adamski, Thermal design of plate heat exchangers applied as condensers or evaporators (in Polish), Współczesne problemy techniki chłodniczej, SITMP, Stow. Prod. i Użytkowników Urządzeń Chłodniczych, Centr. Ośr. Chłodnictwa, (1999) pp. 95-101, Kraków

4. J.R. Thome, Fundamentals of Condensation on Tubes and Tube Bundles, Chap. 7, http://ltcm.epfl.ch/files/content/sites/ltcm/files/shared /import/migration/COURSES/TwoPhaseFlowsAndH eatTransfer/lectures/Chapter_7.pdf

5. L. Albright, Albright's Chemical Engineering Handbook, CRC Press (2009).

6. D. Mikielewicz, Momentum exchange and heat transfer modelling in two-phase bubble flow (in Polish), Gdansk Univ. of Techn. Press (2002)

7. M. Adamski, Longitudinal flow spiral recuperators in building ventilation systems, Energy and Build., 40(2008), pp. 1883-1888 